DECISION MAKING PROCESS: CONCEPTUALIZING

HOW CHINESE AND WESTERN MANAGERS DIFFER

\author{
Mariya Eranova* \\ Nottingham University Business School China \\ 199 Taikang East Road \\ Ningbo 315100 \\ China \\ Mariya.ERANOVA@nottingham.edu.cn \\ Shameen Prashantham \\ Nottingham University Business School China \\ 199 Taikang East Road \\ Ningbo 315100 \\ China \\ Shameen.Prashantham@nottingham.edu.cn
}

7 January 2014

*Corresponding author. 


\title{
DECISION MAKING PROCESS: CONCEPTUALIZING HOW CHINESE AND WESTERN MANAGERS DIFFER
}

\begin{abstract}
In this paper we pose the question: How does the decision making process of Chinese managers differ from that of Western managers? Integrating Chinese notions of thinking with the stages of decision making process, our central argument is that in contrast to Western managers, Chinese managers are more likely to identify problems collectively (rather than set goals individualistically), synthesize conflicting alternative views (rather than analyse mutually exclusive alternatives), and arrive at non-binding solutions (instead of committing to a unique solution). We offer a depiction of the decision making process of Chinese managers, which we show to differ fundamentally from that of Western managers.
\end{abstract}

KEYWORDS: decision making, decision making process, Chinese managers, Chinese-Western differences, emic-etic debate. 


\section{DECISION MAKING PROCESS: CONCEPTUALIZING HOW CHINESE AND WESTERN MANAGERS DIFFER}

\section{INTRODUCTION}

Managerial decision making is a topic of growing interest among Chinaoriented management researchers. Prior work has sought to shed light on Chinese thinking styles (Peng \& Nisbett, 1999; Paik, Groves, Vance, \& Li, 2008), decision modes (Weber, Ames, \& Blais, 2004; Quanyu, Leonard, \& Tong, 1997), decision styles (Chu \& Spires, 2008) and decision strategies (Cheng, Rhodes, \& Lok, 2009). While some work focuses exclusively on Chinese managerial decision making, other studies have sought to draw out comparisons between Chinese and Western managers in relation to aspects such as moral preferences (Paik et al, 2008; Singh, Vitell, AlKhatib, \& Clark III, 2007), probability judgement (Yates, Zhu, Ronis, Wang, Shinotsuka, \& Toda, 1989), overconfidence (Yates, Lee, \& Bush 1997) and indecisiveness (Tse, Lee, Vertinsky, \& Wehrung, 1988; Yates, Ji, Oka, Lee, Shinotsuka, \& Sieck, 2010). In general, the literature indicates that deep-seated cultural differences exist between Chinese and Western managers' decision-making.

However, this literature is surprisingly silent about differences in decision making process - i.e. a sequence of stages from goal setting to choice making between Chinese and Western managers. The dearth of processual research is problematic in that we are afforded only a coarse-grained view of differences between Chinese and Western managers in the literature; vital points of distinction remain undetected within the blackbox of managerial decision making research. From a theoretical perspective, this implies that we have an underspecified account of how decision making unfolds differentially between these culturally diverse sets of managers. From a practical perspective, this means that managers are denied valuable 
insight that might help mitigate frustrations and misunderstandings that abound even as Sino-Western commercial activity continues its upward trajectory.

As an initial attempt to address this gap in the literature, we pose the question:

\section{How does the decision making process of Chinese managers differ from that of}

Western managers? In response, we proffer a conceptualization of differences in goal setting, generating alternatives and choice making between Chinese and Western managers. We do so by drawing upon emic understandings of the nature of Chinese thinking styles encapsulated in the principles of holism (or relationship), contradiction and change (Peng \& Nisbett, 1999). Integrating Chinese notions of thinking with the stages of decision making process, our central argument is that in contrast to Western managers, Chinese managers are more likely to identify problems collectively (rather than set goals individualistically), synthesize conflicting alternative views (rather than analyse mutually exclusive alternatives), and arrive at non-binding solutions (instead of committing to a unique solution) ${ }^{1}$.

Our conceptualization makes two broad contributions to China-oriented management research. First, we offer a depiction of the decision making process - i.e. different stages over time - of Chinese managers, which we show to differ quite fundamentally from that of Western managers. Second, we integrate emic and etic approaches thus providing a compromise-based perspective to the ongoing debate within China-oriented management scholarship about the relative merits of these approaches. Given our interest in contrast we emphasize the 'extreme' forms of what we depict as Western and Chinese approaches to the managerial decision making process. We of course recognize that in reality, each population of managers will contain variance in the extent to which individuals conform to these extreme

\footnotetext{
${ }^{1}$ Furthermore, the boundary conditions of our theory include moderate levels of complexity, adequate levels of authority and the absence of institutional interference.
} 
depictions. Nevertheless we believe that there are theoretical and practical benefits in systematically articulating these contrasts.

\section{THEORETICAL BACKGROUND}

The building blocks of our theorizing are two-fold. First, we draw on Chinese cultural and philosophical notions that impact upon thinking styles and ultimate decision making process. Second, we utilize the conventional depiction of managers' decision making process from literature that takes an essentially Western perspective. We provide a brief overview of these literatures before going on to integrate notions from each in the theory building section.

\section{Thinking Style of Chinese Managers}

Peng and Nisbett (1999) characterise Chinese people as dialectical thinkers ${ }^{2}$. They identify three principles of thinking style emanating from China's distinctive

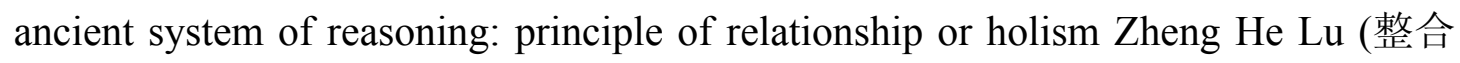
律), principle of contradiction Mao Dun Lu (矛盾律) and principle of change Bian Yi Lu (变异律). We build upon these principles but, given that decision making is a cognitive activity that is closely related, but not identical, to thinking style, it is necessary to augment the discussion of these notions with other cultural and behavioural characteristics of Chinese managers.

One of the main elements that cannot be neglected when talking about managerial decision making is the collectivist orientation of Chinese society, which makes decision making a social process (Xiao \& Su, 2004). Fundamental Chinese values reflect the assumption that an individual is strongly connected with a collective. For example, the concept of Face is defined as an individual's 'awareness about a public image formed in other's mind' (Hwang, 1997: 21); it represents a

\footnotetext{
${ }^{2}$ This does not mean that Westerners are not capable of dialectic thinking ( $\left.\mathrm{Li}, 2013\right)$ but that it is likely to be practised more widely in a Chinese managerial population compared to a Western one.
} 
social image of a person (Kam \& Bond, 2008), and thus, this concept is 'more interpersonally connected' (Chan, 2005: 34). The value of Face makes sense to an individual only in a group. Another characteristic of Chinese culture is a value of Harmony actively discussed in Confucianism and Taoism that also embodies a social dimension. Harmony is associated with creating inner peace in an individual's mind, and represents the ideal of interpersonal relationships in society (Cheung, Leung, Fan, Song, Zhang \& Zhang, 1996). Therefore, the notions of Face and Harmony that were originated in ancient philosophy and that still remain relevant in modern Chinese society could not be developed without collectivistic preconditions. It can therefore be expected that the actual or imagined presence of in-groups is a major determinant of judgmental processes in a Chinese context. We integrate these ideas to inform our understanding of the three principles underpinning Chinese thinking styles, which we briefly describe below.

Principle of Holism. As Peng and Nisbett (1999: 743) point out, the idea of holism 'holds that nothing is isolated and independent, but everything is connected... The holistic mode of thought rests on the assumption that everything exists in the mystical integration of yin and yang, entities that are opposed to one another and yet also are connected in time and space as a whole'. There is no need to prioritize among aspects of a situation, as they all perceived as equally relevant and interconnected. Hence the principle of holism is also referred to as the principle of relationship (Peng \& Nisbett, 1999). Going beyond these authors' description, on the individual level holistic perception of reality refers to the ability to see the self as interdependent with others, as an inseparable part of a collective, and to maintain a constant informational exchange between members of a collective. Thus holism is at the heart of the 
collectivistic tendencies associated with Chinese managers. As Chen (2002: 179) observes:

In contrast to the Western analytic way of thinking, which is based on breaking the whole into parts, the Chinese mindset takes an integrative point of view, one that considers all things in terms of their relationships...

Principle of Contradiction. According to Peng and Nisbett, the principle of contradiction states that 'reality is not precise or cut-and-dried but is full of contradictions... Old and new, good and bad, strong and weak, and so on coexist in everything' (1999: 743). The principle of contradiction, like the principle of holism, is reflected in the notion of Yin Yang that embodies an idea of constant movement of and interaction between opposing forces ${ }^{3}$. Yin Yang forces do not represent isolated objects but rather describe states (Yang, 2006). Therefore, according to the idea of Yin Yang, nothing exists in isolation and there is no absolute substance in the universe: every event, thing or fact should be considered as having a contrasting element in itself, and thus, everything is viewed in relation with its opposition. As Fang (2003: 363) observes, 'Yin Yang represents a paradoxical, integrated, holistic, harmonious, and changing worldview and lifestyle'. Although Yin and Yang represent opposing forces, they should not be understood as contradictory or conflicting (Yang, 2006: 330). Rather, Yin Yang emphasises duality thinking and 'treats all contradictions as permanent yet relative (contrary yet complementary), like the two sides of the same coin at the same level, thus non-resolvable and desirable at all levels' (Li, 2011). In relation to human behaviour, the idea of Yin Yang manifests as a tolerant attitude to multiple truths and paradoxical propositions (Ji, Lee, \& Guo, 2010). Therefore, thinking in accordance with the principle of contradiction refers to

\footnotetext{
${ }^{3}$ We reiterate the point made in footnote 2: duality thinking is not the preserve of, but more socialized within the mainstream population, in China compared to the West.
} 
the ability to accept opposing statements, as both are correct at different points and contain a portion of truth. It enables the development of compromise-based solutions.

Principle of Change. The principle of change is based on the idea that 'reality is a process' and it 'does not stand still but is in a constant flux' (Peng \& Nisbett, 1999: 743). This principle is rooted in ancient Chinese folk assumptions about reality as dynamic and changeable, and therefore 'the concepts that reflect reality are also active, changeable, and subjective rather than being objective, fixed, and identifiable entities' (1999: 743). In addition to the description of Peng and Nisbett (1999), the principle of change also refers to the traditional belief that everything in reality is moving in a non-linear fashion in space and time. This results in repetition of events and cases (situations) and their connection in past, present and future. Since nothing remains the same, even people 'are not valued for what they are, but for what they can become' (Yang, 2006: 339). On the other hand, because of the circular movement, all things and events tend to occur again at different times in different forms and circumstances. For a Chinese mind, there is nothing absolutely new and unknown in everyday life; every phenomenon has already occurred in the past and was experienced by the focal individual or someone else in the in-group. Perceiving reality

as flexible and dynamic results in what might be termed 'pattern thinking' i.e. searching for patterns of Chinese people. The idea of change is also reflected in the Confucian notion of Zhong Yong that expresses the need to behave in accordance with the situation and to avoid extremes in order to maintain harmony.

\section{Managerial decision making process}

Our specific focus is on decision making process. Decision making process entails a sequence of stages - from a goal-setting to making a final choice. The 
decision making process has been depicted as a linear sequence of steps by some (Drucker, 1967; Svenson, 1979; Cyert \& March, 1992), and as cyclical in others (Hoghart, 1987; Montgomery, 1989; Endsley, 1997; Nutt, 1998; Soane \& Nicholson, 2008). Irrespective of the specifics, these models tend to have common characteristics viz. goal setting, generating alternatives and choice making. Before delving into these facets of the process, however, we make some observations about the roots of these models in rational theory and the bounded rationality concept.

In rational choice theory, decision making is choosing the best alternative amongst a variety of option. Classical decision theory defines a decision as the selection of an action from a set of alternative actions' (Dastani, Hulstijn, \& van der Torre, 2003: 765). Rationality is usually specified as 'instrumental' (Hindmoor, 2006; Eriksson, 2011), which implies that 'actions are judged as being rational to the extent that they constitute the best way of achieving some given goals' (Hindmoor, 2006: 2). A rational actor is a figure that has clear expectations and preferences, whose goal is utility maximization and who acts on the basis of self-interest. A rational actor is assumed to choose one alternative among others that will result in the best outcomes. Simon and his colleagues March and Cyert, known in the literature as the Carnegie school (Hosseini, 2003), first expressed their doubts in the ability of rational choice theory to explain actual decision making. They focused on the problem of human perceptions in decision making situations. The aim of a decision maker is not to maximize expected utility, but to 'satisfice' (1955). In other words, people do not pursue the best alternatives, but they choose those options that are good, or just enough to accomplish the task because they operate under 'bounded rationality'.

Simon (1997) suggests that the words 'decision' and 'choice' are interchangeable. At each moment of time, an actor is faced with numerous alternative 
behaviours; decision 'is the process by which one of these alternatives for each moment's behavior is selected to be carried out' (Simon, 1997: 77). Indeed, there is a strong relationship between these two terms: 'both the cause and the effects of decisions are assumed to involve choice: decision-makers make decisions in order to make choices, and the essential result of decisions is choice' (Brunsson, 2007: 13). Decision making can be simply defined as 'choosing what to do' (Klein, 2009: 9). Bazerman's (2006) definition of decision making puts emphasis on its cognitive aspects - judgments. In understanding decision making as choice or judgment the attention is concentrated on the meaning of 'decision', rather than 'making', and thus, decision making is viewed as an ended action. Chia (1994) re-examines the meaning of the term 'decision making'. The author suggests taking into consideration the second word in the term - 'making', as researchers were preoccupied with the meaning of 'decision', which led to shortened and distorted understanding of the term. According to the definition of Chia, decision making is 'will to order' (Chia, 1994).

The accent on the 'making' aspect of decision making comes out as a process perspective. Svenson (1979: 86) proposes that 'human decision making cannot be understood simply by studying final decisions' and suggests the process approach to decision making. Although models of decision making vary in the number of stages and their sequence, their general characteristics are fairly similar. Therefore, a simplified model of decision making process can be represented as a linear sequence of stages: goal-setting, generation of alternatives, and making a choice. We briefly discuss each in turn.

Goal setting. Goal-setting is identifying 'objective which provides the purpose toward which the organization decisions and activities are directed' (Simon, 1997: 142). This is a process that narrows the field of decision content (Soane \& 
Nicholson, 2008). In another Simon's work (1960) the beginning of decision making process is also labelled as 'intelligence' stage that refers to diagnosis the problem; in Hogarth's model (1987) the starting point of the process is called 'structuring the problem', and Nutt (1993) names it 'setting directions'.

Generating alternatives. Generation of alternatives is developing and analysing possible courses of actions (Simon, 1960; Hogarth, 1987). Sometimes identifying solutions and evaluating the course of action are represented as separate stages (Nutt, 1993). However, it can be assumed the step of alternatives' evaluation is rather a part of the final stage - alternative selection or making a choice. The decision process, according to Montgomery, is usually associated with a number of alternatives, with each alternative having its own attributes. Each attribute in turn has its aspects that can be related to values. The decision maker can assess and compare the attractiveness of the attributes.

Choice making. Making a choice is an individual stage that implies analysis and selection of one the generated alternatives (Simon, 1960). In the model of organizational choice, described by Cyert and March (1992), the choice phase can be quite simple, if 'alternatives are generated strictly sequentially' and the chosen alternative is the first that satisfies the objectives; if more than one alternatives developed at the same time, 'a more complicated choice process is required' that involves implementation of decision rules (1992: 102). 


\section{THEORY BUILDING}

Our theory-building approach combines etic and emic approaches in that we examine Chinese decision making through a stylized etic framework emanating from Western research while also drawing on emic perspectives of the influences on Chinese thinking thereby establishing clearly 'the underlying processes that explain differences' (Weber \& Hsee, 2000: 33). It should be noted that we make a number of assumptions in this theory-building effort. First, we assume that the organizational situation involved in decision making is generally familiar to the decision-maker and of no greater than moderate complexity. Second, we assume that the Western and Chinese managers that we compare possess the authority to take decisions and are of comparable authority. Third, we assume that decision-makers are free of interference from the local institutional environment, which in the case of China may even include the Communist Party, and are not deeply socialized in the norms of a culturally different environment. Finally, we assume that the time and financial pressures faced by Chinese and Western managers are moderate and comparable. Below we specify how Western and Chinese managerial decision making differ in relation to a process comprising goal-setting, alternative generation and choice-making on the basis of the principles of holism, contradiction and change. The table below summarizes our key arguments.

\section{Insert Table 1}

\section{Goal-setting}

In relation to goal-setting, the typical Western approach portrayed in the literature is that of individual managers setting a discrete goal. In the Western decision making process, the importance of goal-setting at the outset is crucial because 'decision-makers adopt and implement plans to reach goals...' (Mitchell \& 
Beach, 1990: 16). Notwithstanding criticisms that a linear model of decision making is not always reflected in reality when complex strategic decisions are made (Cohen, March, \& Olsen, 1972), this model retains applicability to managerial decisions of moderate complexity - such as, for instance, a factory manager having to decide how to tackle quality complaints. In such a case, s/he is likely to demonstrate personal agency by setting a goal to meet an acceptable quantified target of quality levels. This goal then becomes the basis for the decision making process; the search for a solution to the problem ends when the goal has been achieved (March \& Simon, 1993).

How do Chinese managers approach the decision making process? The principle of holism suggests that for a Chinese manager, the beginning of a decision making process manifests as recognition of the occurrence a problem. This calls for changing a situation that isn't quite right and therefore needing to be resolved. The problem is not perceived as an individual task of a manager; rather, according to principle of holism, it is viewed as being connected with other problems and affecting other individuals. Thus, although Chinese managers 'think less about abstract principles than do Americans and more about concrete situations' (Sing et al, 2007: 105), there will likely be appreciation of the need for change rather than a clear goal in isolation of other organizational activities. This is consistent with Tse et al's (1988) finding that relative to the West, decision making in China is less specific.

Furthermore, according to the principle of contradiction, in identifying a problem, a Chinese manager takes into consideration various facts and events, even those that conflict with each other ${ }^{4}$. So, in contrast to a Western manager, a Chinese

\footnotetext{
${ }^{4}$ The Chinese language illustrates the principle of contradiction in real life. Perhaps the best-known illustration of a Chinese word made up of paradoxical notions is the word for 'crisis' viz. weiji which is a combination of the words 'threat' and 'opportunity'. Similarly, the word for 'thing(s)' is dongxi which is a combination of the words 'East' and 'West'. This paradoxical feature of Chinese language extends to other practices such as political slogans that might appear inconsistent to Westerners, for example, 'socialist market economy' or 'stability and development' (Faure \& Fang, 2008: 195).
} 
decision maker does not distinguish information and does not focus on particular elements. Since the reality is perceived as a constant move of the things in space and time, there is no actual temporal demarcation between past and present for a Chinese manager. So, the revealed problem is seen as a repeated pattern from the past, rather than as a unique problem occurring at the present moment in relation to a particular individual.

The above idea echoes the principle of change, according to which organizational events and phenomena unfold in a non-linear fashion, it is less likely that a Chinese manager will set a specific goal as the starting point. Chinese cyclic theory of change (Ji et al, 2010) does not establish preconditions for building a linear vision from a goal setting to goal achieving. Goal-orientation is 'more characteristic of Westerners, with their sense for personal agency, than it is of Asians' (Watanabe, cited by Nisbett, 2003: 128). Therefore, for a Chinese manager there is a broader vision of a problem that needs to be solved, rather than identifying a particular goal.

Synthesizing, the above observations suggest that the starting point of Chinese managers' decision making is more akin to problem awareness which is a more diffuse state than the Western manager's more concrete goal orientation. Not specifying a particular goal does not imply in any sense a lower level of competence; indeed, the recognition of a problem triggers positive action. Rather, it suggests a perception among Chinese managers that the current problem is embedded within a wider system comprising people, activities and problems. To illustrate, in contrast to a Western factory manager setting a goal vis-à-vis overcoming quality defects, a Chinese manager's focus is more likely to be on the fact of the problem, and on disseminating this to the consciousness of the collective. In other words, they engage in a social process of problem identification. Hence, we posit: 
Proposition 1: In relation to goal-setting, compared to Western managers, Chinese managers are more likely to identify a shared problem (collectively) rather than to set a discrete goal (individualistically).

\section{Generating alternatives}

In relation to the generation of alternatives, Western managers typically view various options in meeting their desired goal as mutually exclusive. In essence, alternatives are generated through the gathering and processing of relevant information (Svenson, 1979) and the decision-maker's mental simulation of the situation (Beach \& Connolly, 2005). Although the exhaustive generation of alternatives may be infeasible due to humans' bounded rationality (March \& Simon, 1993), it is still the norm that multiple alternative courses of action are generated and considered in parallel. For our hypothetical Western factory manager seeking to achieve a certain improved level of quality, the alternatives generated might include upgrading employee skills, hiring new employees, replacing or supplementing equipment, and enhancing the level of quality monitoring and control.

Chinese managers' holistic perception of the environment leads to a Chinese manager viewing the current situation as being connected temporally or spatially with other situations within the collective while seeking to identify possible courses of action. Collectivist Chinese managers 'are more likely to search externally to others for socially sanctioned decision rules' (Xiao \& Su, 2004: 328). A Chinese manager who views him or herself as an inseparable part of others within the collective also looks to peers in similar situations, in particular those who have gained credibility and recognition. Thus a holistic perspective contrasts with the narrower analytic approach of Western managers. As Weber et al (2004: 113) suggest, Chinese managers are 
'significantly less likely to use calculation-based decision-making than Americans'. By contrast, a Chinese manager is more likely to engage in a non-sequential search for similarities in other situations

The principle of contradiction also suggests that in the decision making process, a Chinese manager constantly interacts with the collective and takes into consideration various judgments of in-groups. Looking at the situation he/she takes into account various opinions and all possible factors, even those that seem conflicting with each other. For a Chinese manager, even apparently unrelated factors may be relevant as per the principle of contradiction. Furthermore, Chinese managers' tendency to avoid extremes affords little scope for categorizing information tightly. As Nisbett (2003) points out, change 'produces contradiction and contradiction causes change; constant change and contradiction imply that it is meaningless to discuss the individual part without considering its relationships with other parts and prior states' (2003: 175-176). In the test with everyday life scenarios that illustrated social conflicts ('mother-daughter conflict'), conducted by Peng and Nisbett (1999), Chinese participants blamed both sides, whereas Americans preferred noncompromising resolutions of conflicts. Therefore, a Chinese manager may be less inclined to develop alternatives that would represent distinct ways to reach the solution, but instead adopt and combine multiple views, even contradictory ones, by taking the strong points of each. That is, the accent is on contextualizing, rather than categorizing, information.

Building on the above, the principle of change which views things moving in a circular way over time means that a Chinese manager anticipates that the solution to a current problem exists in the past experience of someone - perhaps, some colleagues who have more expertise, and therefore, are worthy of emulation. Xiao and $\mathrm{Su}$ (2004: 346) observe: 'In a culture thick in idioms and references to folk history, past history 
is relied on by actors and observers to confer validity and legitimacy'. A Chinese mind identifies parallel courses of action that worked for someone else, even if the situations are not identical. For a Chinese manager this is an efficient way to address the problem. 'Asians often utilize the decision mode of 'precedence matching' (Zhang, 1992, cited by Xiao \& Su, 2004: 346). Thus, Chinese managers might even search folk history for a precedent that appears relevant instead of undertaking detailed analysis of available information, as Western managers typically do. When a precedent is found, the Chinese decision-maker likely pursues it to the exclusion of further processing of decision-specific details.

Taken together, the picture we get is one of active engagement with alternatives that are potentially viewed as synergistic even if they appear to the linearly-oriented Western mind. Conceptually, a Western factory manager is likely to view the alternative approaches of upgrading existing employees and replacing employees as fundamentally different courses of action ${ }^{5}$. This is not necessarily so for a Chinese manager. Rather than treating these as separate alternatives, a Chinese manager might be inclined to synthesize these into a single alternative around 'employee improvement'. In this way we would expect a smaller but more complex set of alternatives to be generated by Chinese managers compared to Western managers. Therefore:

Proposition 2: In relation to generating alternatives, compared to Western managers, Chinese managers are more likely to synthesize alternative views into 'compromise' options, rather than analyse alternatives as mutually exclusive options.

\footnotetext{
${ }^{5}$ Here the focus is on differences in thinking about alternatives. Of course, even Western managers may be forced to make compromises while implementing decisions owing to stakeholder pressures (e.g. strong trade unions protecting the position of extant employees).
} 


\section{Choice-making}

In relation to making a choice from among the generated alternatives, Western managers can normally be expected to commit to a unique course of action to meet the desired goal. Decision-makers have to assess the payoffs, and difficulties, associated with various potential courses of action (Klein, 1997). The norm in making this choice is adopting a reason-based approach to consider the "balance for and against the various alternatives' (Shafir, Simonson \& Tversky, 1993). Decisionmakers make choices having compared alternatives with reference to their present situation (Kahneman \& Tversky, 1979) in order to arrive at the 'one alternative that can be seen as dominant over the others' (Montgomery, 1989: 23). In the case of the hypothetical Western factory manager seeking to attain a certain quality level, this means making a choice to, for instance, enhance quality monitoring and control.

According to the principle of holism, any solution is not perceived as an ultimate perfect solution. Chinese managers' minds also likely consider other possible solutions. A Chinese manager is inclined to try different possibilities suggested by the members of a collective. Acting in accordance with the principle of holism means that a Chinese manager sees a few possible ways to solve a problem and does not prioritize any, as no one is seen as having the absolutely 'right' answer. A Chinese manager is also concerned with the consequences of the chosen course of action for the collective and his or her reputation in the eyes of in-groups. A synthesis of solutions based on various views of in-groups is possible even if these views contradict each other.

In relation to the principle of contradiction, as there were no preconditions for setting a particular goal at the beginning of the decision making process, no firm decisions are developed purely on the basis of logical deduction in the end. Similar to 
the principle of holism, a Chinese manager acknowledges the possible advantages of several solutions, rather than focusing on one. Faced with a choice between contradictory courses of action, a Chinese decision maker would be inclined to search for a compromise-based option. Therefore, a selected solution may well be an aggregation of the strongest points of a few alternatives.

The principle of change indicates that as at the goal-setting stage, the task of a Chinese manager is to project how things will change in the future, as the situation will not be constant. Empirical investigations demonstrate the ability of Chinese people to predict change; they do it more often and more accurately, compared to American participants (Ji, Nisbett \& Su, 2001). Consistent with the principles of contradiction and change, the final solution may be suboptimal to the present situation but considers changes in the future, which is reflective of the typically long-term orientation of Chinese managers (Hofstede \& Bond, 1988). Hence results may not be immediate, and Chinese managers are far more comfortable with this state of affairs than Western counterparts. For example, in stock decisions 'Chinese participants would be more likely than Americans to keep or buy falling stocks and sell rising stocks' (Ji et al, 2010).

Integrating the above, we envisage Chinese managers to arrive at a solution to deal with the initially recognized problem, albeit without the sense of finality of a goal-oriented Western manager's 'done deal'. For Chinese managers, their initial social process of problem identification suggests a more fluid perspective of what will likely work and the alternative to be chosen. Furthermore, there is likely to be recognition that promising solutions do not always work out and that unpromising solutions may actually do. Thus a Chinese factory manager may proceed on the basis of an 'employee improvement' choice, fully aware that things might not improve and 
if so then other options, perhaps upgrading the equipment, will possibly need to be experimented with. In other words, we expect more tentative, and thus ultimately slower, decision making on the part of Chinese managers relative to their Western counterparts. But equally, once a firm decision is arrived at we also expect a longerterm view, rather than short-termism, to influence that decision Hence, we suggest:

Proposition 3a: In relation to choice making, compared to Western managers, Chinese managers are more likely to arrive at a non-binding solution, rather than commit to a unique solution, initially.

Proposition 3b: In relation to choice making, compared to Western managers, Chinese managers are more likely to arrive at a long-term oriented solution, rather than focus solely on the short-term shared problem, eventually.

\section{DISCUSSION}

We have sought to conceptualize differences in the managerial decision making process between Chinese and Western managers in order to address a lacuna in the extant literature. We focus on differences in relation to goal setting, generating alternatives and choice making by drawing on Chinese principles of holism, contradiction and change. Below we discuss contributions, limitations, future research directions and managerial implications.

\section{Distinctiveness of Chinese managers' decision making process}

The first set of contributions we make is that we offer a depiction of the decision making process - i.e. different stages over time - of Chinese managers, which we show to differ quite fundamentally from that of Western managers. This represents an advance on prior research in a number of ways. 
First, our research extends previous cross-sectional work on differences in choices between Chinese and Western manager by imputing a processual understanding of how managers arrive at their choices. For example, while Tse et al (1988) demonstrate that Chinese managers are less decisive than their Western counterparts, they do so only through cross-sectional data thus providing little sense of how these choices are made. By focusing on decision making process, we are able to clarify that apparent indecisiveness may more accurately be described as tentativeness about solutions, and this follows from differences in the initiation (problem versus goal) and unfolding (synthesis versus analysis) of the decision making process, reflecting the Chinese principles of holism, contradiction and change.

Second, we also extend work such as Weber et al (2004) which did try to shed light on the 'how' of decision making by providing a temporally more nuanced and fine-grained understanding of the process than they do. Without question, Weber et al's (2004) work on decision mode (distinguishing between calculation-, recognitionand affect-based modes) represents an advance on research such as Tse et al (1988) which simply identifies managers' end-choices. But even so, Weber et al's (2004) study, while innovative, is also cross-sectional and thus devoid of a temporallysensitive explication of the managerial decision making process in China as compared to the West. Our depiction of the Chinese managerial decision making process - in particular the manner in which alternatives are generated - fits with what they term a recognition-based mode. In particular, what we describe is akin to an approach that 'evokes memory of similar situations that have been seen and solved in the past' (Weber et al, 2004: 89) and would suggest that Chinese managers will have a bias to recognition-based generation of alternatives relative to the calculation-based mode; and certainly to a greater extent than their Western counterparts. These expectations 
are entirely consistent with their findings. Thus, because our conceptualization is temporally based, it provides a nice complement to Weber et al (2004).

Third, we challenge claims of the decision making process between Chinese and Western managers being essentially similar. For instance, our conceptualization suggests that Quanyu et al (1997: 81) understate key differences when they opine that 'the step of collecting and analysing information is basically similar to each of the steps when comparing decision making in China and the West'. In similar vein they go on to aver that 'formulating and choosing schemes is about the same as selecting alternatives in the West' (1997: 85). We disagree. Our message is clearly that all things being equal, Chinese managers' decision making process is fundamentally different from that of Western managers. Our approach is distinct from presenting polar opposites of continuums as is customary in cross-cultural research. Rather, we highlight key differences e.g. goal-setting versus identifying a problem which are qualitatively distinct. This may be in part because we assume away the influence of cross-cultural socialization; but this seems likely to be true of multitudes of managers operating in mainland China. Thus in highlighting the distinctiveness of the decision making process of Chinese managers, we shed light on modern-day managerial manifestations of traditional cultural orientations in China.

\section{Integrating Emic and Etic Perspectives}

A second broad area of contribution lies in our attempt to integrate etic and emic approaches - that is, applying Western theories to Chinese phenomena and developing uniquely Chinese theory (Morris, Leung, Ames, \& Lickel, 1999), respectively. We provide a compromise-based perspective to the ongoing debate within China-oriented management scholarship about the relative merits of these 
approaches ${ }^{6}$. Our contention is that for research exploring differences between Chinese and Western managers, a purely etic or emic approach is suboptimal. On the one hand, the adoption of a purely etic approach to research in China could highlight demonstrable cultural differences between China and Western countries but will likely yield an inadequate or oversimplified understanding of Chinese managerial phenomena. On the other, purely emic studies in Chinese management research literature (e.g., Fang, 2011) could provide a deeper understanding of the specific features of Chinese context in a way that is relatively independent from Western biases. And overly detailed descriptions of Chinese philosophical concepts and their meanings would transform management research into research on culturology and philosophy. Moreover, it would be difficult to demonstrate how the ancient teachings of Confucius or Lao-tzu directly impact on decision making of modern managers.

An adequate understanding of the process of decision making in China cannot be achieved without taking into consideration indigenous research. However, it should not be limited to the discussion of philosophic texts of ancient China or some aspects of ideational systems, but also include an analysis of other contextual components that belong to material systems and institutional outcomes (Child, 2009: 62). Defining the Chinese context's specific features provide a basis for constructing a model of decision making in China. After a new model is represented, research can move to 'etic' phase which implies finding an appropriate or similar theory (or theories) to the new one in Western tradition.

Hence, rather than adopt a purely emic perspective that highlights differences with no reference whatsoever to the dominant models in the Western literature, we provide a basis for conceptualizing corresponding differences viz. a stylized decision

\footnotetext{
${ }^{6}$ Arguably, in so doing we are mimicking the Chinese managers we describe as being comfortable with integrating apparently conflicting perspectives!
} 
making process (Drucker, 1967; Svenson, 1979; Cyert \& March, 1992). Yet we apply this model with due respect to deep-grained cultural, philosophical and epistemological differences stemming from emic understandings; hence our adoption of Peng and Nisbett's (1999) three principles underlying Chinese thinking styles as an underpinning of our theory-building. This approach is consistent with scholars who agree that in order to construct objective unbiased research it is necessary to take into account both developments of Western theoretical tradition and findings of indigenous research (Barney \& Zhang, 2009; Whetten, 2009; Leung, 2009; Von Glinow \& Teagarden, 2009).

\section{Limitations and Future Research}

Researchers seeking to refine our ideas conceptually and test them empirically should be cognizant of the limitations and boundary conditions of our work. The nature of decisions that our theorizing best applies to are likely to be moderately complex decisions made by autonomous managers who are not socialized in a different culture and not overly constrained by institutional pressures. Also, we are aware that theoretical efforts of this nature almost inevitably portray extreme caricatures of the phenomena among which (sharp) distinctions are made (see Li, 2013 for a recent critique). In explicating differences between Chinese and Western managers we focus exclusively on the three principles highlighted by Peng and Nisbett (1999). While our selectivity in this regard yields parsimony and analytic cohesion we recognize that other influences may be overlooked. Future research could seek a more comprehensive perspective of the cultural and philosophical underpinnings of decision making process. Moreover, we portray the default Western decision making process in relatively simple (even simplistic) terms despite the portrayal of circular (rather than linear) and complex processes even among Western 
managers. However for the sake of analytic clarity we confine our analysis to the simple model. In our defence, such an approach does apply in the real world to decision making of low to moderate complexity. We expect the broad distinctions that we surface to hold under greater complexity. In any event, future research could fruitfully extend our analysis to more complex processes. Our point is that comparing the decision making process of Chinese and Western managers reflects fundamental differences rather than polar opposites. Conceptual work of this nature is, at its heart, agenda setting and we hope ours stimulates further work in this area.

\section{Managerial Implications}

If our propositions find empirical support then our theorizing holds valuable managerial implications. First, a greater mutual awareness of the underlying decision making process could lead to improved cross-cultural Sino-Western dealings. Even if one doesn't quite comprehend why these differences arise, knowing the very fact that they do exist can lead to adjusted expectations and more sympathetic reactions in settings such as negotiations about exchange transactions and in joint ventures.

Second, greater self-awareness of the decision making process could lead to Chinese managers considering when their natural instincts are likely to be effective and when not. In certain situations, compromise-oriented thinking can lead to a desirable balance between effecting change and preserving harmony, yet in other situations may lead to dysfunctional indecisiveness. Third, paying greater attention to Chinese proclivities could be potentially instructive to Western managers in relation to dealing with the contradictions inherent in organizational life (e.g. simultaneously pursuing exploration and exploitation) and in addressing decisions of long-term significance. While their natural linear decision making process can be effective in many cases, in certain instances a Chinese-style decision making process could be more efficacious. 


\section{Conclusion}

Weber et al (2004: 87) observe that 'actions taken by an organization are frequently the direct consequence of a decision made by one or more of its managers'. The process by which managers arrive at decisions is influenced by a multitude of factors including the nature of the decision, pressures under which the decision is made and decision-maker characteristics. While there is an emergent literature examining differences between Chinese and Western managerial decisions, a comparison of processual aspects has been largely overlooked. By drawing upon the Chinese principles of holism, contradiction and change, we have sought to conceptualize how Chinese and Western managers differ in their manner of setting goals, generating alternatives and making choices. This work adds to the literature comparing the decisions (rather than decision making process) of Chinese and Western managers. Refining and testing these ideas represents, we believe, a fruitful research area for the future. 


\section{REFERENCES}

Barney, J.B., \& Zhang, S. (2009). The future of Chinese management research: A theory of Chinese management versus Chinese theory of management. Management and Organization Review, 5 (1): 15-28.

Bazerman, M.H. (2006). Judgment in managerial decision making, $\left(6^{\text {th }} \mathrm{ed}\right)$, Hoboken N.L.: J. Whiley.

Brunsson, N. (2007). The consequences of decision-making. New York: Oxford University Press.

Buchanan, L., \& O'Connell, A. (2006). A brief history of decision making. Harvard Business Review, January.

Chan, B. (2005). From West to East: The impact of culture on personality and group dynamics. Cross Cultural Management, 12 (1): 31-45.

Cheung, F.M., Leung, K., Fan, R.M., Song W.Z., Zhang J.X., \& Zhang, J.P. (1996). Development of the Chinese Personality Assessment Inventory. Journal of CrossCultural Psychology, 27: 181-199.

Chen, M-J. (2002). Transcending paradox: The Chinese "middle way" perspective. Asia Pacific Journal of Management, 19: 179-199.

Cheng, V., Rhodes, J., \& Lok, P. (2010). A framework for strategic decision making and performance among Chinese managers. The International Journal of Human Resource Management, 21 (9): 1373-1395.

Chia, R. (1994). The concept of decision: A deconstructive analysis. Journal of Management Studies, 31 (6): 781-806.

Child, J. (2009). Context, comparison, and methodology in Chinese management research. Management and Organization Review, 5 (1): 57-73.

Chu, P.R., \& Spires, E.E. (2008). The cost-benefit framework and perceptions of decision strategies. Journal of Cross-Cultural Psychology, 39 (3): 303-308.

Cohen, M.D., March, J.G., \& Olsen, J.P. (1972). A Garbage Can model of organizational choice. Administrative Science Quarterly, 17 (1): 1-25.

Cyert, R.M., \& March, J.G. (1992). A behavioral theory of the firm, (2 $2^{\text {nd }}$ ed.). Oxford: Blackwell Business.

Cyert, R.M., Simon, H.A., \& Trow, D.B. (1956). Observation of a business decision. The Journal of Business, 29 (4): 237-248.

Dastani, M., Hulstijn, J., \& Torre, L. (2005). How to decide what to do? European Journal of Operational Research, 160: 762-784.

Drucker, P.F. (1967). The effective decision. Harvard Business Review, JanuaryFebruary.

Endsley, M.R. (1997). The role of situation awareness in Naturalistic Decision Making. In: C. Zsambok, \& G.A. Klein (Eds.), Naturalistic Decision Making, (pp. 269-283), Mahwah, N.J.: L. Erlbaum Associates.

Eriksson, L. (2011). Rational choice theory: Potential and limits. Basingstoke: Palgrave Macmillan. 
Fang, T. (2003). A critique of Hofstede's fifth national culture dimension. International Journal of Cross-Cultural Management, 3 (3): 347-368.

Fang, T. (2011). Yin Yang: A new perspective on culture. Management and Organization Review, 8 (1): 25-50.

Faure, G.O., \& Fang, T. (2008). Changes Chinese values: Keeping up with paradoxes. International Business Review, 17: 194-207.

Hindmoor, A. (2006). Rational Choice. Basingstoke: Palgrave Macmillan.

Hofstede, G., \& Bond, M.H. 1988. The Confucius connection: From cultural roots to economic growth. Organizational Dynamics, 16(4): 4-21.

Hogarth, R.M. (1987). Judgment and choice: The psychology of decision. Chichester: Wiley.

Hosseini, H. (2003). The arrival of behavioral economics: from Michigan, or the Carnegie school in the 1950s and the early 1960s? Journal of Socio-Economics, 32: 391-409.

Hsu, F.L.K. (1953). Americans and Chinese: Two ways of life. New York: H. Schuman.

Hwang, K.K. (1997). Guanxi and Mientze: Conflict resolution in Chinese society. International Communication Studies, 8 (1): 17-38.

Ji, L.J., Lee, A., \& Guo, T. (2010). The thinking styles of Chinese people. In: M.H. Bond, (Ed.), The Oxford handbook of Chinese psychology, (pp. 155-168). New York: Oxford University Press.

Ji, L.J., Nisbett, R.E., \& Su, Y. (2001). Culture, change, and prediction. Psychological Science, 12 (6): 450-456.

Kahneman, D., \& Tversky, A. (1979). Prospect theory: An analysis of decision under risk. Econometria, 47 (2): 263-282.

Kam, C.C.S., \& Bond, M.H. (2008). Role of emotions and behavioral responses in meditating the impact of face loss on relationship deterioration: Are Chinese more face-sensitive than Americans? Asian Journal of Social Psychology, 11: 175-184.

Klein, G.A. (1997). The Recognition-Primed Decision (RPD) Model: Looking Back, Looking Forward. In: C. Zsambok, \& G.A. Klein (Eds.), Naturalistic Decision Making, (pp. 138-147). Mahwah, N.J.: L. Erlbaum Associates.

Klein, G.A. (2009). Streetlights and shadows: Searching for the keys to adaptive decision making. Cambridge: MIT Press.

Leung, K. (2009). Never the twain shall meet? Integrating Chinese and Western Management research. Management and Organization Review, 5 (1): 121-129.

Li, P.P. (2011). Toward an integrative framework of indigenous research: The geocentric implications of Yin-Yang balance. Asia Pacific Journal of Management, 29 (4): 849-872.

March, J.G. \& Simon, H.A. (1993). Organizations, (2 ${ }^{\text {nd }}$ ed). Cambridge: Blackwell.

Mitchell, T.R. and Beach, L.R. (1990). “...Do I Love Thee? Let Me Count...” Toward an understanding of intuitive and automatic decision making. Organizational Behavior and Human Decision Processes, 47: 1-20. 
Montgomery, H. (1989). From cognition to action: The search for dominance in decision making. In: H. Montgomery, \& O. Svenson, (Eds.), Process and structure in human decision making, (pp. 23-49). Oxford: John Wiley \& Sons.

Morris, M.W., Leung, K., Ames, D., \& Lickel, B. (1999). Views from inside and outside: integrating emic and etic insights about culture and justice judgment. Academy of Management Review, 24 (4): 781-796.

Nisbett, R.E. (2003). The geography of thought: How Asians and Westerners think differently and why. London: Nicholas Brealey.

Nutt, P.C. (1993). The identification of solution ideas during organizational decision making. Management Science, 39 (9): 1071-1085.

Nutt, P.C. (1998). How decision makers evaluate alternatives and the influence of complexity. Management Science, 44 (8): 1148-1166.

Paik, Y., Groves, K.S., Vance, C.M., \& Li, D.H. (2008). Linking linear/nonlinear thinking style balance and managerial ethical decision-making. Journal of Business Ethics, 80 (2): 305-325.

Peng, K. \& Nisbett, R.E. (1999). Culture, dialectics, and reasoning about contradiction. American Psychologists, 54 (9): 741-754.

Quanyu, H., Leonard, J.W., \& Chen, T. (1997). Business Decision Making in China. New York: International Business Press.

Shafir, E., Simonson, I., \& Tversky, A. (1993). Reason-based choice. Cognition, 49: 11-36.

Simon, H.A. (1955). A behavioral model of rational choice. The Quarterly Journal of Economics, 69 (1): 99-118.

Simon, H.A. (1960). The new science of managerial decision, New York: Harper and Row.

Simon, H.A. (1997). Administrative behavior: A study of decision-making processes in administrative organizations, $\left(4^{\text {th }} \mathrm{ed}\right)$, New York: Free Press.

Singh, J.J., Vitell, S.J., Al-Khatib, J., \& ClarkIII, I. (2007). The role of moral intensity and personal moral philosophies in the ethical decision making of marketers: A crosscultural comparison of China and the United States. Journal of International Marketing, 15 (2): 86-112.

Svenson, O. (1979). Process descriptions of decision making. Organizational Behaviour and Human Performance, 23: 86-112.

Tse, D.K., Lee, K.H., Vertinsky, I., \& Wehrung, D.A. (1988). Does culture matters? A cross-cultural study of executives' choice, decisiveness, and risk adjustment in international marketing. Journal of Marketing, 52: 81-95.

Von Glinow, M.A. \& Teagarden, M.B. (2009). The future of Chinese management research: rigour and redux. Management and Organization Review, 5 (1): 75-89.

Weber, E.U., Ames, D.R., \& Blais, A. (2004). 'How do I choose Thee? Let me count the ways': A textual analysis of similarities and differences in models of decisionmaking in China and the United States. Management and Organizational Review, 1 (1): 87-118. 
Weber, E.U., \& Hsee, C.K. (2000). Culture and individual judgments and decision making. Applied Psychology: An International Review, 49 (1): 32-61.

Whetten, D.A. (2009). An examination of the interface between context and theory applied to the study of Chinese organizations. Management and Organization Review, 5 (1): 29-55.

Xiao, Z., \& Su, S.K. (2004). Keeping others in mind: A very social cognition of Asian managers. In: Leung, K., \& White, S. (Eds.), Handbook of Asian Management, (pp. 315-347), Hingham: Kluwer Academic Publishers.

Yang, C.F. (2006). The Chinese conception of the Self: Towards a person-making perspective. In: U. Kim, K.S. Yang, K.K. Hwang, (Eds.), Indigenous and cultural psychology: Understanding people in context, (pp. 327-356). New York: Springer.

Yates, J.F., Zhu, Y., Ronis, D.L., Wang, D.F., Shinotsuka, H., \& Toda, M. (1989). Probability judgment accuracy: China, Japan, and the United States. Organizational Behavior and Human Decision Processes, 43: 145-171.

Yates, J.F., Lee, J.W., \& Bush, J.C. (1997). General knowledge overconfidence: cross-national variations, response style, and "reality". Organizational Behavior and Human Decision Processes, 70 (2): 87-94.

Yates, J.F., Ji, L.J., Oka, T., Lee, J.W., Shinotsuka, H., \& Seick, W.R. (2010). Indecisiveness and culture: Incidence, Values, and Thoroughness. Journal of CrossCultural Psychology, 41 (3): 428-444.

Zey, M. (1998). Rational choice theory and organizational theory: a critique. London: Sage Publications. 
Table 1. COMPARISON OF WESTERN AND CHINESE MANAGERIAL DECISION MAKING

\begin{tabular}{|c|c|c|c|}
\hline & Goal-setting & Generation of alternatives & Choice-making \\
\hline 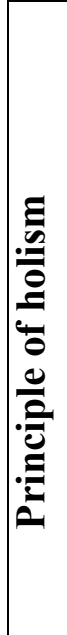 & $\begin{array}{l}\text { Personal agency and linear } \\
\text { orientation toward the goal } \\
\text { Vs. Broad need for change } \\
\text { that affects everyone } \\
\text { (Nisbett, 2003). }\end{array}$ & $\begin{array}{l}\text { Problem led: isolating the } \\
\text { problem and looking for an } \\
\text { appropriate solution Vs. } \\
\text { Solution led: accepting } \\
\text { multiple solutions; } \\
\text { Collective discussion but } \\
\text { individual analysis Vs. } \\
\text { pattern identification } \\
\text { through collective } \\
\text { information exchange (Peng } \\
\text { \& Nisbett, 1999; Xiao \& Su, } \\
\text { 2004). }\end{array}$ & $\begin{array}{l}\text { Decisive commitment } \\
\text { to unique solution, } \\
\text { making a choice } \\
\text { individually Vs. } \\
\text { Synthesis of solutions } \\
\text { based on various } \\
\text { suggestions of in- } \\
\text { groups (Peng \& Nisbett, } \\
\text { 1999; Xiao \& Su, } \\
\text { 2004). }\end{array}$ \\
\hline 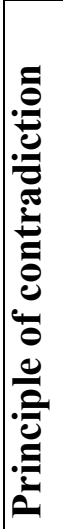 & $\begin{array}{l}\text { Distinguishing } \\
\text { information, building a } \\
\text { chain of causality and } \\
\text { setting an appropriate goal } \\
\text { Vs. Accepting } \\
\text { contradictions, avoiding } \\
\text { extremes and finding a } \\
\text { similar case in the } \\
\text { information flow (Peng \& } \\
\text { Nisbett, 1999). }\end{array}$ & $\begin{array}{l}\text { Categorizing information } \\
\text { Vs. Contextualizing } \\
\text { information (Nisbett, 2003; } \\
\text { Faure \& Fang, 2008). }\end{array}$ & $\begin{array}{l}\text { Commitment to one } \\
\text { unique solution Vs. } \\
\text { Acknowledging truth of } \\
\text { multiple solutions, even } \\
\text { if they contradict with } \\
\text { each other (Faure \& } \\
\text { Fang, 2008). }\end{array}$ \\
\hline 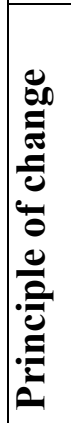 & $\begin{array}{l}\text { Attempts to control the } \\
\text { current situation, finding a } \\
\text { starting point to set a goal } \\
\text { Vs. Attempts to predict } \\
\text { future change, no starting } \\
\text { point as the situation is } \\
\text { changing over time (Ji et } \\
\text { al, 2010). }\end{array}$ & $\begin{array}{l}\text { Matching current actions } \\
\text { with future desired } \\
\text { outcomes, treating the } \\
\text { current case as unique Vs. } \\
\text { Matching present situation } \\
\text { with future change through } \\
\text { finding a pattern in the past } \\
\text { (Xiao \& Su, 2004). }\end{array}$ & $\begin{array}{l}\text { Seeking optimal } \\
\text { solution for now Vs. } \\
\text { Seeking optimal } \\
\text { solution for future } \\
\text { (which may be } \\
\text { suboptimal for now) ( Ji } \\
\text { et al, 2001; Ji et al, } \\
2010 \text { ). }\end{array}$ \\
\hline
\end{tabular}

